\title{
Optimal adaptation to extreme rainfalls in current and future climate
}

\section{Rosbjerg, Dan}

Published in:

Water Resources Research

Link to article, DOI:

10.1002/2016WR019718

Publication date:

2017

Document Version

Peer reviewed version

Link back to DTU Orbit

\section{Citation (APA):}

Rosbjerg, D. (2017). Optimal adaptation to extreme rainfalls in current and future climate. Water Resources Research, 53(1), 535-543. https://doi.org/10.1002/2016WR019718

\section{General rights}

Copyright and moral rights for the publications made accessible in the public portal are retained by the authors and/or other copyright owners and it is a condition of accessing publications that users recognise and abide by the legal requirements associated with these rights.

- Users may download and print one copy of any publication from the public portal for the purpose of private study or research.

- You may not further distribute the material or use it for any profit-making activity or commercial gain

- You may freely distribute the URL identifying the publication in the public portal

If you believe that this document breaches copyright please contact us providing details, and we will remove access to the work immediately and investigate your claim. 


\title{
Optimal adaptation to extreme rainfalls in current and future climate
}

\author{
Dan Rosbjerg \\ Department of Environmental Engineering, Technical University of Denmark, DK-2800 Kongens \\ Lyngby
}

\begin{abstract}
More intense and frequent rainfalls have increased the number of urban flooding events in recent years, prompting adaptation efforts. Economic optimization is considered an efficient tool to decide on the design level for adaptation. The costs associated with a flooding to the $T$-year level and the annual capital and operational costs of adapting to this level are described with log-linear relations. The total flooding costs are developed as the expected annual damage of flooding above the $T$-year level plus the annual capital and operational costs for ensuring no flooding below the $T$-year level. The value of the return period $T$ that corresponds to the minimum of the sum of these costs will then be the optimal adaptation level.

The change in climate, however, is expected to continue in the next century, which calls for expansion of the above model. The change can be expressed in terms of a climate factor (the ratio between the future and the current design level) which is assumed to increase in time. This implies increasing costs of flooding in the future for many places in the world. The optimal adaptation level is found for immediate as well as for delayed adaptation. In these cases the optimum is determined by considering the net present value of the incurred costs during a sufficiently long time span. Immediate as well as delayed adaptation is considered.
\end{abstract}

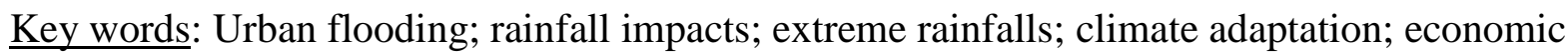
optimization.

\section{Introduction}

Pluvial flooding of cities has become more frequent in recent years creating awareness of the needs for adaptation efforts. The increasing frequency of flooding has been attributed to climate change, and quite a few papers have assessed the expected development in urban rainfall extremes and the needs for adaptation efforts, e.g., Willems et al. (2012), Gregersen and Arnbjerg-Nielsen (2012), Arnbjerg-Nielsen et al. (2013) and Merz et al. (2014). Even without taking the changing climate into account it might be advantageous to revisit the urban drainage system in the light of current flooding risk. Urban drainage systems are generally designed by regulatory demands for safety return periods and thus not based on economic optimality. 
Risk of flooding can be assessed in economic terms using the Expected Annual Damage (EAD) concept (e.g., Chow et al., 1988). A method for analyzing the profitability of adaptation projects (e.g. Zhou et al., 2012, 2013) is to carry out a series of cost-benefit calculations and comparing Net Present Values $(N P V)$ of all encured costs and benefits. The $N P V$ is the difference between the present value of benefits (reduction in damage costs) and the present value of construction and maintenance costs during the considered time period. While this can assure profitableness, it does not necessarily provide an optimal solution.

Fortunato et al. (2014) presented a procedure for obtaining the optimal design rainfall return period for urban drainage systems by minimizing the sum of $E A D$ and the Equivalent Annual Costs (EAC) defined as the sum of annual capital and operational costs. The analysis, however, did not take climate development into account.

In the following the $E A D$ concept will be thoroughly introduced, and then elaborated in the case of a log-linear relation between rainfall with return period $T$ and the related damage $D(T)$ (e.g. Zhou et al., 2012 and Olsen et al., 2014). After adaptation, different modifications of the damage function will be considered. Then the optimal level of adaptation in current climate will be addressed assuming a log-linear relation between the return period $T$ and the corresponding annual costs of adapting to this level. Contrary to Fortunato et al. (2014) the emphasis is laid on analytical solutions. However, by using numerical integration techniques results can be found as well, should the analytical requirements not be fulfilled.

In a changing climate $E A D$ will increase during time in many places in the world, and therefore the Net Present Value (NPV) of all incurred costs during a sufficient long period should be minimized. After introducing a Climate Factor $(C F)$ defined as the ratio between the design rain in a future changing climate and the design rain in the current climate the minimum $N P V$ and the optimal adaptation level will be determined, while taking into account both immediate and delayed adaptation. Finally, the obtained results will be discussed and concluded.

\section{Expected Annual Damage}

If the $T$-year rainfall level is denoted $x_{T}$ and the corresponding damage $D_{x}\left(x_{T}\right)$, the Expected Annual Damage $(E A D)$ is obtained by the integral

$$
E A D=\int_{x_{T_{s}}}^{\infty} D_{x}\left(x_{T}\right) f_{X}\left(x_{T}\right) d x_{T}=\int_{x_{T_{s}}}^{\infty} D_{x}\left(x_{T}\right) d F_{X}\left(x_{T}\right)
$$

where $f_{X}\left(x_{T}\right)$ is the probability density function of the annual rainfall maximum, $F_{X}\left(x_{T}\right)$ is the cumulative distribution function, and $x_{T S}$ is the lowest level that implies damage costs. Here it is implicitly assumed that the $T$-year level refers to an annual maximum series, from which the $T$-year levels can be estimated. The exceedance probability of the $T$-year level is denoted $p=1-F_{X}\left(x_{T}\right)$. Thus we have $x_{T}=F^{-1}(1-p)$ and $d F_{X}\left(x_{T}\right)=-d p$, implying that 


$$
E A D=\int_{0}^{p_{s}} D_{p}(p) d p
$$

where the argument in the damage function has been replaced such that $D_{X}\left(x_{T}\right)=D_{p}(p)$. This formulation is well-known (e.g., Chow et al., 1988) and often utilized for calculation of $E A D$, although it is evident that it is difficult (impossible) to obtain values of the damage function for $p$ close to 0 .

In the following it is, however, more convenient to calculate $E A D$ by integration over the return period, $T$. Using that $p=1 / T$ and $d p=-1 / T^{2} d T$, we get

$$
E A D=\int_{T_{s}}^{\infty} \frac{D(T)}{T^{2}} d T
$$

where the argument in the damage function again has been replaced such that now $D(T)=D_{p}(p)$. The integrand in Eq. (3) will be denoted risk density, $c f$. the notation probability density.

\subsection{Log-linear damage function}

It is now assumed that the damage function can be written as a log-linear relation, as observed by Zhou et al. (2012) and Olsen et al. (2014)

$$
D(T)=a \ln T+b \quad \text { where } \quad D(T)=0 \quad \text { for } \quad T=T_{0}=\exp \left(-\frac{b}{a}\right)
$$

For $T_{0} \geq 1$ yr we get by integration of either Eq. (2) or Eq. (3)

$$
E A D=a \exp \left(\frac{b}{a}\right)=\frac{a}{T_{0}}
$$

assuming that damage will start where $D(T)=0$. If damage starts at $T_{s} \geq T_{0}$, and $T_{s} \geq 1 \mathrm{yr}$, we get

$$
E A D=\frac{a}{T_{s}}\left(1+\ln \frac{T_{s}}{T_{0}}\right)=a h\left(T_{s}\right)
$$

whereby the function $h$ has been introduced.

\subsection{EAD after adaptation to the $T$-year level}

After adaptation to the $T$-year level damage will now start at this level. $E A D$ will then depend on the form of the damage curve after adaptation. We will consider four cases

- a damage curve shifted such that damage will start from 0 at the $T$-year level instead of at $T_{0}$ (or $\left.T_{s}\right)$

- a shifted damage curve but with a changed slope 
- the original damage curve being kept except that no damage will happen below the $T$-year level

- a gradual change from the shifted to the original damage curve depending on a form parameter $\gamma$, see Fig. 1.

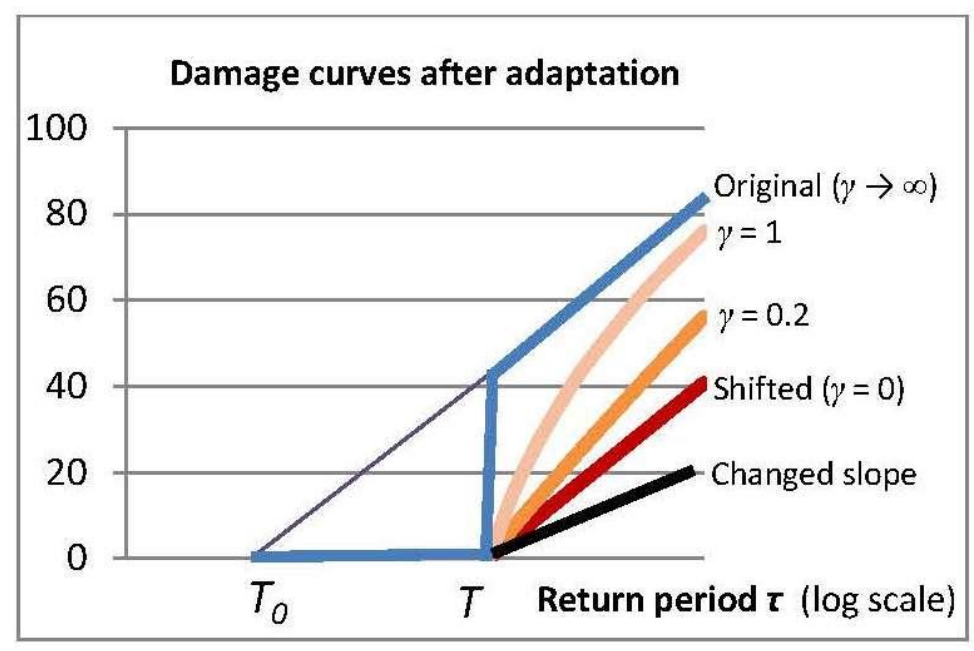

Fig. 1 Damage curves after adaptation to the $T$-year level.

Shifted damage curve

In this case we get

$$
E A D(T)=\int_{T}^{\infty} \frac{D(\tau)-D(T)}{\tau^{2}} d \tau=\frac{a}{T}
$$

\section{Changed slope above T}

Provided that a new slope of the damage curve $k a$ is valid for all $T>T_{s}$, where a slope correction factor $k$ has been introduced, we get

$$
E A D(T)=\frac{k a}{T}
$$

Original damage curve above $T$

Here we find

$$
E A D(T)=\int_{T}^{\infty} \frac{D(\tau)}{\tau^{2}} d \tau=\frac{a}{T}\left(1+\ln \frac{T}{T_{0}}\right)
$$

Gradual change from 0 to the original damage curve 
By introducing a form parameter $\gamma(0 \leq \gamma<\infty)$, we get

$$
E A D(T)=\int_{T}^{\infty} \frac{D(\tau)-D(T)\left(\frac{\tau}{T}\right)^{-\gamma}}{\tau^{2}} d \tau=\frac{a}{T}\left(1+\left(1-\frac{1}{1+\gamma}\right) \ln \frac{T}{T_{0}}\right)
$$

where $\gamma=0$ corresponds to the shifted damage curve, and $\gamma \rightarrow \infty$ corresponds to the original curve. In general we have $E A D(T)=a g(T)$, where $g$ can take on different forms depending on the actual conditions.

\section{Optimal adaptation level in current climate}

A plausible assumption may be that the equivalent annual costs $E A C$ (capital and operational costs) corresponding to climate adaptation to the $T$-year level approximately follows a log-linear relation, as for example the data applied by Fortunato et al. (2014). Thus

$$
E A C(T)=c \ln T+d
$$

For the total annual costs $T A C$ we get

$$
T A C(T)=E A D(T)+E A C(T)
$$

where $E A D$ depends on the prevailing damage curve after adaptation. Obviously, the optimal adaptation level in an economic sense will be the one that minimizes TAC.

Shifted damage curve

By insertion of $E A D$ from Eq. 7 we get

$$
T A C(T)=\frac{a}{T}+c \ln T+d
$$

Setting the derivative equal to 0 leads to

$$
T_{o p t}=\frac{a}{c}
$$

Changed slope above T

Here we can just substitute $a$ with the new slope using a correction factor $k$

$$
T_{o p t}=\frac{k a}{c}
$$

Original damage curve above $T$ 
Using Eq. (9) TAC becomes

$$
T A C(T)=\frac{a}{T}\left(1+\ln \frac{T}{T_{0}}\right)+c \ln T+d
$$

Setting the derivative equal to 0 leads to

$$
T-\frac{a}{c} \ln \frac{T}{T_{0}}=0
$$

from which $T_{\text {opt }}$ can easily be found by iteration.

Gradually changed damage curve

For TAC we obtain using Eq. (10)

$$
T A C(T)=\frac{a}{T}\left(1+\left(1-\frac{1}{1+\gamma}\right) \ln \frac{T}{T_{0}}\right)+c \ln T+d
$$

Putting the derivative equal to 0 leads to

$$
T-\frac{a}{c}\left[\left(1-\frac{1}{1+\gamma}\right) \ln \frac{T}{T_{0}}+\frac{1}{1+\gamma}\right]=0
$$

where $T_{o p t}$ again can be found by iteration.

\section{Optimal adaptation in future climate}

It can be approximately assumed that the climate factor $C F$ (the ratio between future and current design rain) develops with time as a linear function (e.g. Park et al., 2010). Thus

$$
C F(t) \approx 1+\theta t \quad \Rightarrow \quad \theta=\frac{C F(L)-1}{L}
$$

where $L$ is the time horizon for the climate adaptation. Approximately the factor $a$ in the log-linear damage relation will be proportional to the climate factor, see Appendix 1. Thus

$$
a(t)=a C F(t)=a(1+\theta t)
$$

For $E A D$ we have

$$
E A D(t, T)=a(t) g(T)
$$

where the function $g(T)$ depends on the actual damage curve. For immediate adaptation the Net Present Value $(N P V)$ of all incurred costs assuming a discount rate $r$ can then be expressed 


$$
N P V(T)=\sum_{t=1}^{L}(a(t) g(T)+E A C(T))(1+r)^{-t}
$$

and the optimal return period level determined indirectly by finding

$$
N P V\left(T_{o p t}\right)=\min _{T} N P V(T)
$$

Taking delayed adaptation into account, optimization can be carried out with respect to both $T$ and $t *$ where $t *$ is the adaptation time. The $N P V$ becomes

$$
N P V\left(t_{*}, T\right)=\sum_{t=1}^{t_{*}} a(t) h\left(T_{s}\right)(1+r)^{-t}+\sum_{t=t_{*}+1}^{L}(a(t) g(T)+E A C(T))(1+r)^{-t}
$$

and

$$
\min _{t_{*}, T} N P V\left(t_{*}, T\right)
$$

will provide the optimal combination of adaptation time and adaptation level. For a fixed chosen adaptation time a conditionally optimal $T$ can be found. In Appendix 2 closed form solutions for the Net Present Values and optimal $T$-values are developed assuming that the shifted damage function is valid.

In the general case the $N P V$ is presented in closed form in Appendix 3 together with an equation from which the optimal $T$-value can be found by iteration. Prevailing values for adaptation time $t *$, discount rate $r$, gradient in the climate factor $\theta$, slope in the log-linear damage function $a$, return period for which the log-linear damage function is zero $T_{0}$, return period where damage starts $T_{s}$, slope correction parameter in the damage function after adaptation $k$, form parameter in the damage function after adaptation $\gamma$ and slope in the log-linear adaptation cost function $c$ can be applied.

\section{Example}

The damage costs for the different levels of extreme rain in Table 1 have been adopted from Olsen et al. (2014). The data originate from the city of Odense in Denmark and may not be representative for other cities. They approximately follow a log-linear relation and are as such representative for a number of analyzed cases. $T *$ in the first row denotes return periods estimated in partial duration (or peak over threshold) series. In the second row $T *$ has for $T * \leq 10 \mathrm{yr}$ been transformed to annual maximum series return periods using the formula (Rosbjerg, 1977)

$$
T=\left[1-\exp \left(-\frac{1}{T_{*}}\right)\right]^{-1}
$$

Table 1 Damage costs as function of return periods for extreme rainfall (adopted from Olsen et al. (2014). 


\begin{tabular}{|c|c|c|c|c|c|c|c|c|c|c|c|c|c|c|c|c|c|}
\hline$T_{*}$ & $(\mathrm{yr})$ & 2 & 3 & 5 & 7 & 10 & 20 & 50 & 60 & 75 & 100 & 125 & 150 & 200 & 250 & 500 & 1000 \\
\hline$T$ & $(\mathrm{yr})$ & 2,54 & 3,53 & 5,52 & 7,51 & 10,5 & 20 & 50 & 60 & 75 & 100 & 125 & 150 & 200 & 250 & 500 & 1000 \\
\hline$D(T)$ & $\left(10^{6} \mathrm{DKK}\right)$ & 2 & 5 & 7 & 8 & 10 & 21 & 8 & 34 & 36 & 39 & 45 & 47 & 55 & 57 & 70 & 82 \\
\hline
\end{tabular}

The plot in Fig. 2 confirms an approximate log-linear relation between return period and damage costs. The risk density is shown in Fig. 3.

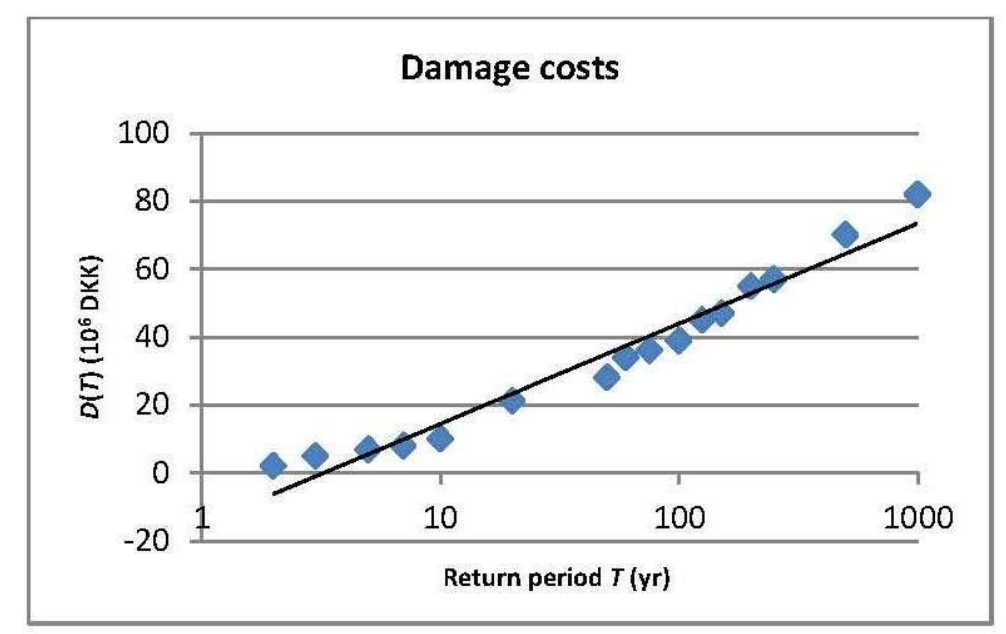

Fig. 2 Damage costs as function of the return period of extreme rainfalls.

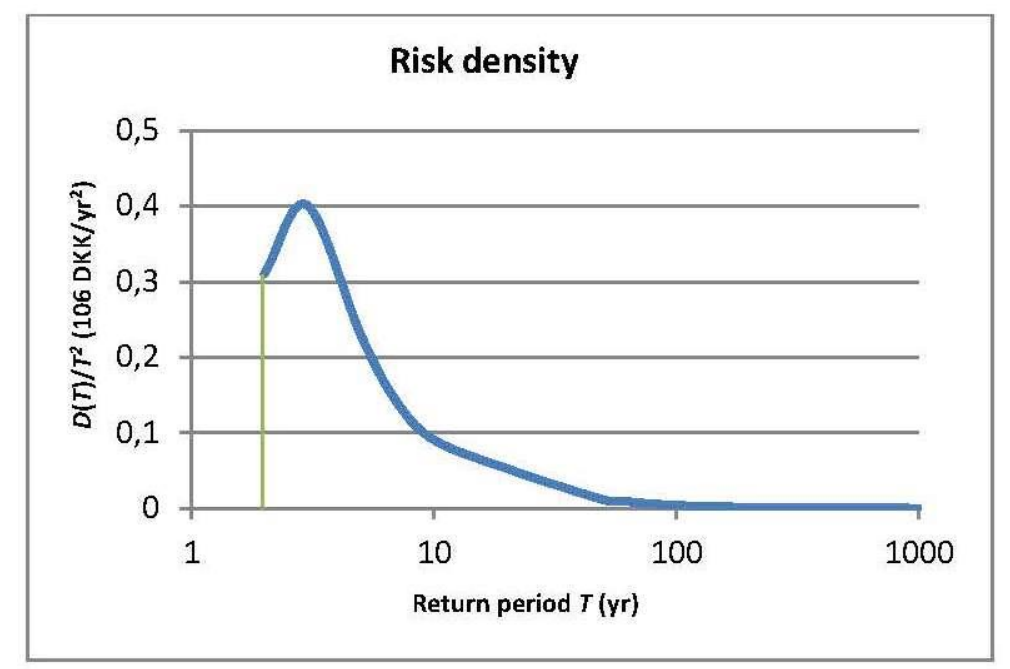

Fig. 3 Risk density as function of the return period of extreme rainfalls.

From Fig. 3 it is seen that the contribution from rare events to the $E A D$ is minor.

To obtain the parameters for optimization we plot the damage curve using natural logarithms of $T$ in Fig. 4. 


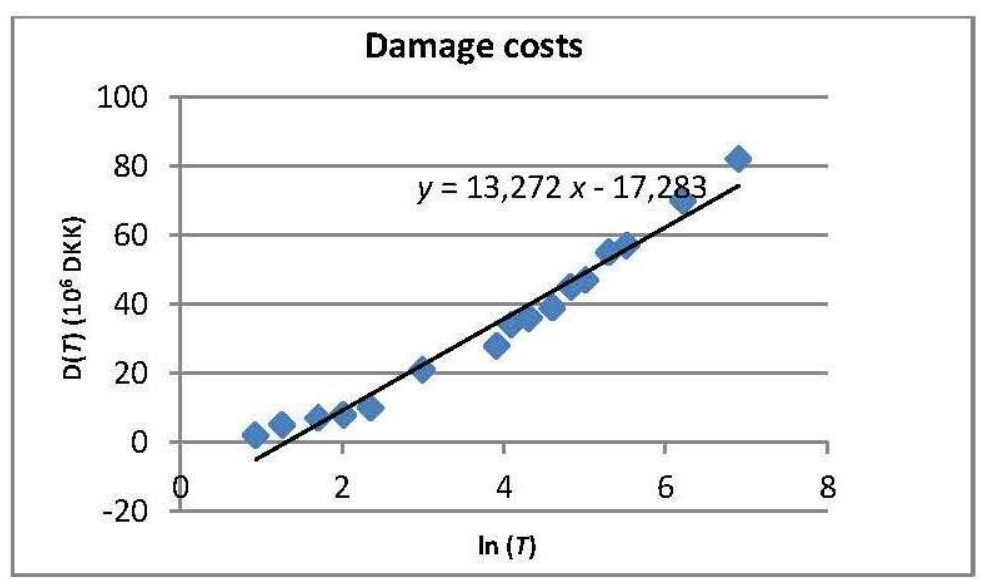

Fig 4. Damage costs as function of the natural logarithm of $T$.

It is seen that $a=13.3 \cdot 10^{6} \mathrm{DDK} / \mathrm{yr}$ and $b=-17.3 \cdot 10^{6} \mathrm{DDK} / \mathrm{yr}$. Thus from Eq. (4) $T_{0}=3.67 \mathrm{yr}>$ $1 \mathrm{yr}$, and from Eq. (5) we get $E A D=3.62 \cdot 10^{6} \mathrm{DDK} / \mathrm{yr}$.

Estimation of the adaptation costs as function of the adaptation level has led to the values $c=0.5$. $10^{6} \mathrm{DDK} / \mathrm{yr}$ and $d=-0.65 \cdot 10^{6} \mathrm{DDK} / \mathrm{yr}$ in Eq. (11).

\subsection{Adaptation in current climate}

Assuming that the shifted damage curve is valid, we obtain from Eq. (14) that $T_{\text {opt }}=26.6 \mathrm{yr}$ and from Eq. (13) that $T A C\left(T_{o p t}\right)=1.49 \cdot 10^{6} \mathrm{DDK} / \mathrm{yr}$. These results are illustrated in Fig. 5.

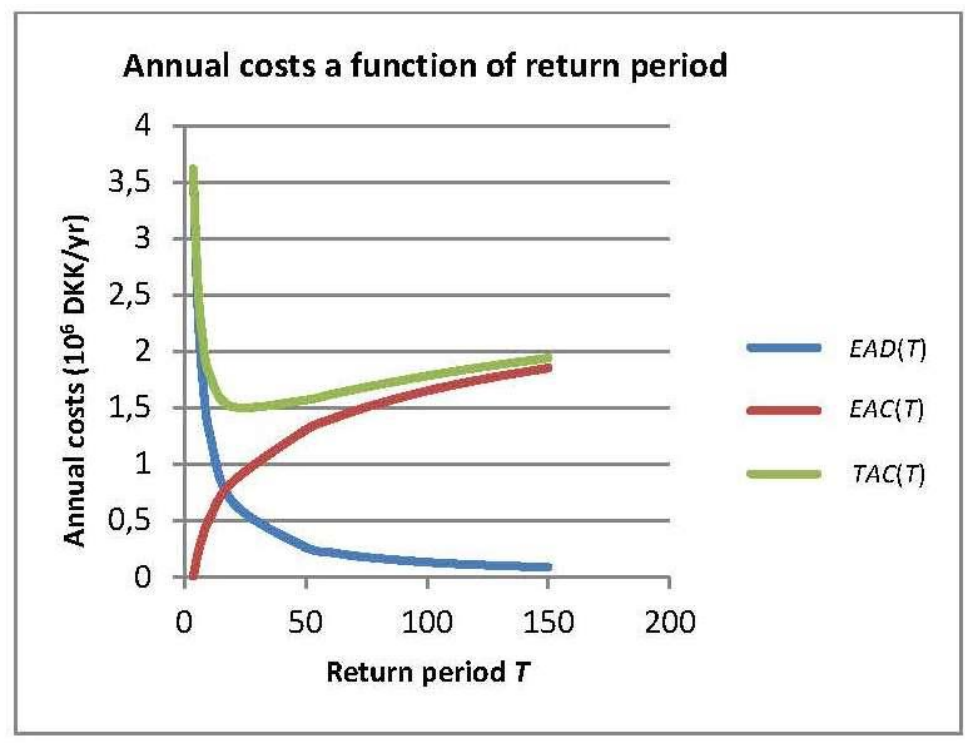

Fig. 5 Annual costs as function of the return period.

As can be noted from Fig. 5, it is much more expensive to underestimate than overestimate the optimal return period. This is also evident from the results of Fortunato et al. (2014). 
An indication of the uncertainty in the obtained optimal return period can obtained usig a simple first order analysis leading to

$$
C V_{T_{o p t}} \approx \sqrt{C V_{a}^{2}+C V_{c}^{2}}
$$

Thus a $10 \%$ uncertainty in both $a$ and $c$ will lead to a $14 \%$ uncertainty in $T_{\text {opt }}$.

\subsection{Adaptation in future climate}

Let us assume that the shifted damage curve still is valid and that $L=100 \mathrm{yr}$ and $r=0.03$. Two different climate factors are considered, $C F(L)=1.4$ and $C F(L)=1.7$.

\section{Immediate adaptation}

By using Eqs. (23) or (A2.2) we can plot the net present value as function of the return period in Fig. 6.

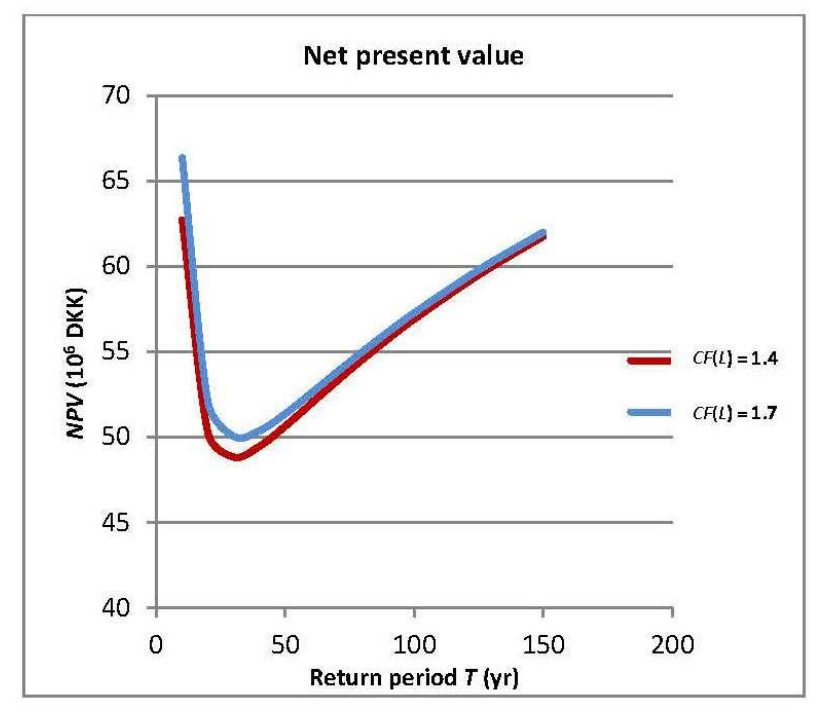

Fig. 6 Net present value of all incurred costs as function of the return period.

It is seen that that the optimal return period has increased slightly. Using Eq. (A2.4) we get $T_{o p t}=$ $29.6 \mathrm{yr}$ for $C F(L)=1.4$ and $T_{\text {opt }}=31.8 \mathrm{yr}$ for $C F(L)=1.7$. Using Eq. (A2.2) the minimum net present value is found to $48.9 \cdot 10^{6} \mathrm{DDK} / \mathrm{yr}$ for $C F(L)=1.4$ and $50.0 \cdot 10^{6} \mathrm{DDK} / \mathrm{yr}$ for $C F(L)=1.7$.

It should be noticed that inclusion of climate development in the example sharpens the minimum such that due to the increasing damage costs with time the tendency for overestimation to be more expensive than underestimation becomes less pronounced.

\section{Delayed adaptation}

By use of Eqs. (25) or (A2.1) the effect of delayed adaptation can be analyzed. In the present case the optimal adaptation level $T_{\text {opt }}$ is moderately increased, see Fig. A2.1. Growth in the NPV minimum with delay time, however, is pronounced, see Fig. 7. This is primarily attributed to the 
expected flooding costs encountered before the adaptation has taken place. Both figures also show the relative effects of the different climate factors.

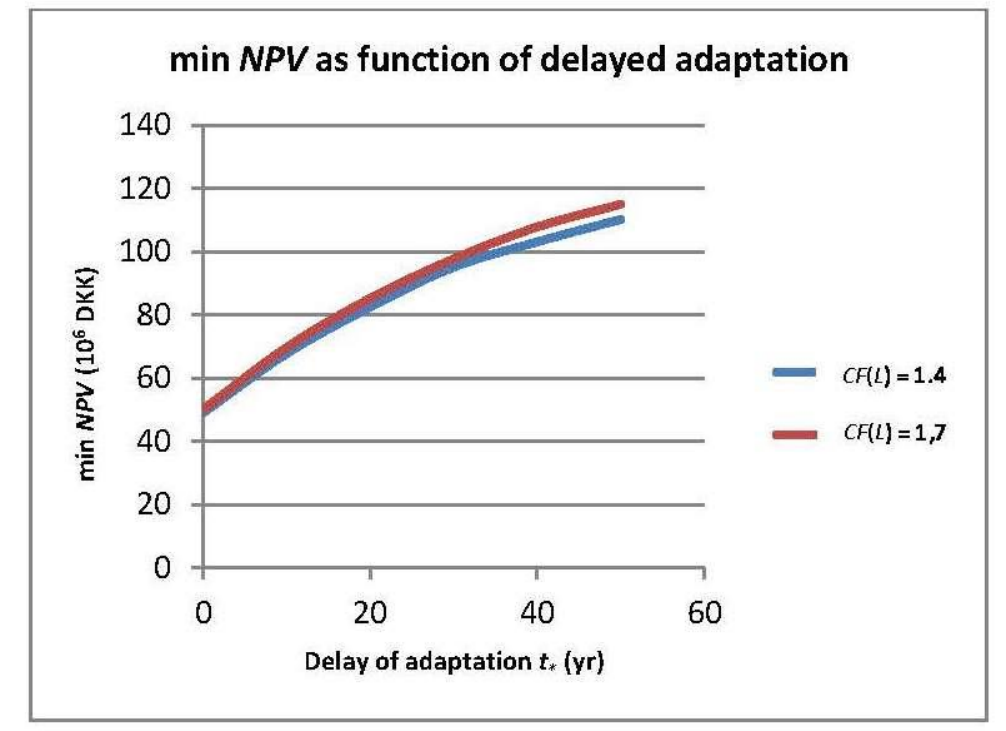

Fig. 7 Minimum of $N P V$ as function of delayed adaptation.

\section{Discussion}

The optimization has been presented using log-linear relations for both the damage costs caused by extreme rainfall with a given return period and for the costs of adaptation to such rainfalls, which provides analytical advantages. Although these relations appear plausible, they may not always be fulfilled. Therefore, it should be emphasized that the developed optimization procedure can also be carried out with arbitrary cost functions using numerical integration.

Uncertainty is inherent in the economic calculations. Cost functions are often crude estimates, and parameters like the discount rate can always be discussed. Another contribution to uncertainty is the linkage between the return period and the extreme rainfall magnitude. This is outside the scope of the present paper, but has been thoroughly treated by Arnell (1989). Altogether these different sources of uncertainty make it advisable to carry out a sensitivity analysis before a final decision is taken.

\section{Conclusions}

A procedure for estimating the optimal adaptation level in economic terms has been developed and exemplified using log-linear functions for the damage caused by extreme rainfalls and the costs of adapting to these rainfalls. Solutions corresponding to different options for how the damage cost function may change after adaptation have been considered, and corresponding expressions for the expected annual damage after adaptation have been developed. Optimal adaptation levels in 
economic terms have been determined in the cases of both immediate and delayed adaptation. For immediate adaptation the total annual costs have been minimized, while for delayed adaptation the net present value was minimized. The results indicate that the optimal adaptation level is relatively stable, if a shifted damage curve is valid, but delaying the adaptation raises the costs notably, primarily due to expected damage costs until the adaptation is carried out. Due to the uncertainty involved in economic optimization the found optimum should not be considered the final answer, but rather a starting point for more refined design efforts.

\section{Acknowledgements}

The author is grateful for the valuable reviewer comments by Patrick Willems and two anonumous reviewers, which have been very helpful for strengthening the paper. Data used in the paper are available in referenced literature.

\section{References}

Arnbjerg-Nielsen, K., P. Willems, J. Olsson, S. Beecham, A. Pathirana, I. B. Gregersen, H. Madsen and V.-T.-V. Nguyen (2013) Impacts of climate change on rainfall extremes and urban drainage systems: a review, Water Science and Technology 68(1), 16-28.

Arnell, N. W: (1989) Expected annual damages and uncertainties in flood frequency estimation, Journal of Water Resources Planning and Management 115(1), 94-107.

Chow, V. T., D. R. Maidment and L. W. Mays (1988) Applied Hydrology, McGraw-Hill.

Gregersen, I. B. and K. Arnbjerg-Nielsen (2012) Decision strategies for handling the uncertainty of future extreme rainfall under the influence of climate change, Water Science and Technology $\mathbf{6 6}(2)$, 284-291.

Fortunato, A., E. Oliveri and M. R. Mazzola (2014) Selection of the optimal design rainfall return period of urban drainage systems, Procedia Engineering 89, 742-749.

Merz, B., J. Aerts, K. Arnbjerg-Nielsen, M. Baldi, A. Becker, A. Bichet, G. Blöschl, L. M. Bouwer, A. Brauer, F. Cioffi, J. M. Delgado, M. Gocht, F. Guzzetti, S. Harrigan, K. Hirschboeck, C. Kilsby, W. Kron, H.-H. Kwon, U. Lall, R. Merz, K. Nissen, P. Salvetti, T. Swiercynski, U. Ulbrich, A. Viglione, P. J. Ward, M. Weiler, B. Wilhelm and M. Nied (2014) Floods and climate: emerging perspectives for flood risk assessment and management, Natural Hazards and Earth System Sciences 14, 1921-1942.

Olsen, A. S., Q. Zhou, J. J. Linde and K. Arnbjerg-Nielsen (2014) Comparing methods of calculating expected annual damage in urban pluvial flood risk assessments, Water 7, 255-270. 
Park, J.-S., H-S. Kang, Y. S. Lee and M.-K. Kim (2011) Changes in the extreme daily rainfall in South Korea, International Journal of Climatology 31, 2290-2299.

Rosbjerg, D. (1977) Return periods of hydrological events, Nordic Hydrology 8(1), 57-61.

Willems, P., K. Arnbjerg-Nielsen, J. Olsson and V.-T.-V. Nguyen (2012) Climate change impact assessment on urban rainfall extremes and urban drainage: Methods and shortcomings, Atmospheric Research 103, 106-118.

Zhou, Q., P. S. Mikkelsen, K. Halsnæs and K. Arnbjerg-Nielsen (2012) Framework for economic pluvial risk assessment considering climate change effects and adaptation benefits, Journal of Hydrology 414-415, 539-549.

Zhou, Q., T. E. Panduro, B. J. Jellesmark and K. Arnbjerg-Nielsen (2013) Adaption to extreme rainfall with open urban drainage system: An integrated hydrological cost-benefit analysis, Environmental Management 51, 586-601.

\section{Appendix 1: Relation between climate factor and slope of damage function}

Consider the situation at the end of the planning period, say after $L$ years. The design rain without climate change is denoted $x_{L}$ and with accountancy of climate change $\xi_{L}$. Thus

$$
\xi_{L}=C F(L) x_{L}
$$

The corresponding return periods are

$$
T_{\xi_{L}}=\frac{1}{1-F_{X}\left(\xi_{L}\right)} \quad \text { and } \quad T_{x_{L}}=\frac{1}{1-F_{X}\left(x_{L}\right)}
$$

It is anticipated that the cost of exceeding $x_{L}$ in $L$ years' time will equal the cost of exceeding $\xi_{L}$ today

$$
a(L) \ln T_{x_{L}}+b=a \ln T_{\xi_{L}}+b
$$

This implies that

$$
a(L)=a \frac{\ln \frac{1}{1-F_{X}\left(\xi_{L}\right)}}{\ln \frac{1}{1-F_{X}\left(x_{L}\right)}}=a \frac{\ln \left(1-F_{X}\left(\xi_{L}\right)\right)}{\ln \left(1-F_{X}\left(x_{L}\right)\right)}
$$

Now assume that $F_{X}$ approximately has exponential tail behavior, that is $F_{X}(x) \approx 1-\exp (-\lambda x)$. Then 


$$
a(L) \approx a \frac{\xi_{L}}{x_{L}}=a C F(L)
$$

\section{Appendix 2: NPV and $T_{o p t}$ assuming a shifted damage function}

In the case of a shifted damage function and $T_{s}=T_{0}$ the continuous counterpart to Eq. (25) can be written

$$
\begin{aligned}
& N P V\left(t_{*}, T\right)=\int_{0}^{t_{*}} E A D\left(t, T_{0}\right) e^{-r t} d t+\int_{t_{*}}^{L}(E A D(t, T)+E A C(t, T)) e^{-r t} d t \\
& =\frac{a}{T_{0}} \int_{0}^{t_{*}} e^{-r t} d t+\frac{a \theta}{T_{0}} \int_{0}^{t_{*}} t e^{-r t} d t+\frac{a}{T} \int_{t_{*}}^{L} e^{-r t} d t+\frac{a \theta}{T} \int_{t_{*}}^{L} t e^{-r t} d t+(c \ln T+d) \int_{t_{*}}^{L} e^{-r t} d t \\
& =\left(\frac{a}{r T_{0}}+\frac{a \theta}{r^{2} T_{0}}\right)\left(1-e^{-r t_{*}}\right)-\frac{a \theta}{r T_{0}} t_{*} e^{-r t_{*}}+\left(\frac{a}{r T}+\frac{a \theta}{r^{2} T}\right)\left(e^{-r t_{*}}-e^{-r L}\right) \\
& \quad+\frac{a \theta}{r T}\left(t_{*} e^{-r t_{*}}-L e^{-r L}\right)+\left(\frac{c}{r} \ln T+\frac{d}{r}\right)\left(e^{-r t_{*}}-e^{-r L}\right)
\end{aligned}
$$

In the special case of $t *=$, i.e. immediate adaptation, we get

$$
N P V(T)=\left(\frac{a}{r T}+\frac{a \theta}{r^{2} T}+\frac{c}{r} \ln T+\frac{d}{r}\right)\left(1-e^{-r L}\right)-\frac{a \theta L}{r T} e^{-r L}
$$

Setting the derivative of Eq. (A2.1) with respect to $T$ equal to 0 and solving for $T$ result in

$$
T_{o p t}\left(t_{*}\right)=\frac{\left(1+\frac{\theta}{r}\right)\left(e^{-r t_{*}}-e^{-r L}\right)+\theta\left(t_{*} e^{-r t_{*}}-L e^{-r L}\right)}{\frac{c}{a}\left(e^{-r t_{*}}-e^{-r L}\right)}
$$

which in the special case of $t_{*}=0$ gives the optimal $T$-year level for immediate adaptation

$$
T_{o p t}=\frac{\left(1+\frac{\theta}{r}\right)\left(1-e^{-r L}\right)-\theta L e^{-r L}}{\frac{c}{a}\left(1-e^{-r L}\right)}
$$

Eq. (A2.3) is illustrated in Fig. A2.1 with use of the same parameters as introduced in the example. 


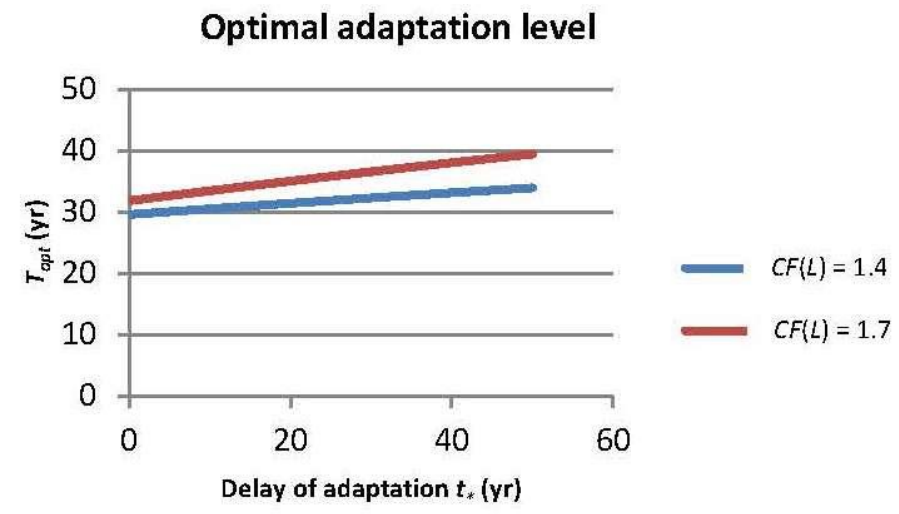

Fig. A2.1 Optimal adaptation level as function of adaptation delay.

It can be seen that a delay will moderatelyly increase the optimal return period.

\section{Appendix 3: $N P V$ and $T_{o p t}$ in the general case}

In the general case the net present value becomes

$$
\begin{aligned}
N P V\left(t_{*}, T\right)= & \left(\frac{a}{r T_{0}}+\frac{a \theta}{r^{2} T_{0}}+\frac{a}{T_{s}} \ln \frac{T_{s}}{T_{0}}+\frac{a \theta}{r^{2} T_{s}} \ln \frac{T_{s}}{T_{0}}\right)\left(1-e^{-r t_{*}}\right)-\left(\frac{a \theta}{r T_{0}}+\frac{a \theta}{r T_{s}} \ln \frac{T_{s}}{T_{0}}\right) t_{*} e^{-r t_{*}} \\
& +\left(\frac{a}{r T}+\frac{a \theta}{r^{2} T}\right)\left(e^{-r t_{*}}-e^{-r L}\right) \\
& +\frac{k a}{r T}\left[1+\left(1-\frac{1}{1+\gamma}\right) \ln \frac{T}{T_{0}}\right]\left[\left(1+\frac{\theta}{r}\right)\left(e^{-r t_{*}}-e^{-r L}\right)+\theta\left(t_{*} e^{-r t_{*}}-L e^{-r L}\right)\right] \\
& +\left(\frac{c}{r} \ln T+\frac{d}{r}\right)\left(e^{-r t_{*}}-e^{-r L}\right)
\end{aligned}
$$

and the optimal return period must be found by iteration in the expression

$$
T-\frac{\left(\frac{1}{1+\gamma}+\left(1-\frac{1}{1+\gamma}\right) \ln \frac{T}{T_{0}}\right)\left[\left(1+\frac{\theta}{r}\right)\left(e^{-r t_{*}}-e^{-r L}\right)+\theta\left(t_{*} e^{-r t_{*}}-L e^{-r L}\right)\right]}{\frac{c}{k a}\left(e^{-r t_{*}}-e^{-r L}\right)}=0
$$

